\title{
Alisol A 24-Acetate Prevents Hepatic Steatosis and Metabolic Disorders in HepG2 Cells
}

\author{
Lu Zeng $^{\mathrm{a}}$ WaiJiao Tang ${ }^{\mathrm{b}}$ JinJin Yin ${ }^{\mathrm{c}}$ LiJuan Feng ${ }^{\mathrm{d}}$ Yabing Li $^{\mathrm{e}}$ Xiaorui Yao ${ }^{\mathrm{b}}$ \\ BenJie Zhou ${ }^{b}$
}

\begin{abstract}
aDepartment of Pharmacy, Ganzhou People's Hospital, Nanchang University, Jiangxi, Ganzhou, ${ }^{b}$ Department of Pharmacy, Zhujiang Hospital, Southern Medical University, Guangdong, 'Department of Pharmacy, The Third Affiliated Hospital of Guangzhou Medical University, 'Department of Pharmacy, Beijiao Hospital, Southern Medical University, Guangdong, eDepartment of Pharmacy, Guangdong Provincial Maternity and Child Care Hospital, Guangdong, PR China
\end{abstract}

\section{Key Words}

Alisol A 24-acetate - Hepatic steatosis - Lipid accumulation • Inflammation - Adiponectin • $\mathrm{AMPK} \alpha \cdot \operatorname{PPAR} \alpha$

\begin{abstract}
Background: Non-alcoholic fatty liver disease (NAFLD) is closely associated with metabolic disorders including hepatic lipid accumulation and inflammation. Alisol A 24-acetate, a triterpene from Alismatis rhizome, has multiple biologic activities such as hypolipidemic, antiinflammatory and anti-diabetic. Thus we hypothesized that Alisol A 24 -acetate would have effect on NAFLD. The present study was conducted to investigate the therapeutic effects and potential mechanisms of Alisol A 24-acetate against hepatic steatosis in a free fatty acids (FFAs) induced NAFLD cell model. Methods: This study was divided into four groups including Control group, Model group (FFA group), Alisol A 24-acetate (FFA+A) group, Fenofibrate $(\mathrm{FFA}+\mathrm{F})$ group. Preventive role of Alisol A 24-acetate was evaluated using $10 \mu \mathrm{M}$ Alisol A 24-acetate plus $1 \mathrm{mM}$ FFA (oleate:palmitate $=2: 1$ ) incubated with HepG2 cells for 24 h, which was determined by Oil Red $O$ Staining, Oil Red $O$ based colorimetric assay and intracellular triglyceride (TG) content. Besides, the inflammatory cytokines tumor necrosis factor (TNF)- $\alpha$, interleukin (IL)- 6 levels as well as the protein and mRNA expressions that were involved in fatty acid synthesis and oxidation including Adiponectin, AMP-activated protein kinase (AMPK) $\alpha$, peroxisome proliferator-activated receptor (PPAR) $\alpha$, sterol regulatory element binding protein 1c (SREBP-1C), acetyl-CoA carboxylase (ACC), fatty acid synthase (FAS), carnitine palmitoyltransferase 1 (CPT1) and acyl coenzyme A oxidase 1 (ACOX1) were detected. Results: Alisol A 24-acetate significantly decreased the numbers of lipid droplets, Oil Red O lipid content, and intracellular TG content. Besides, inflammatory cytokines TNF- $\alpha$, IL- 6 levels were markedly inhibited by Alisol A 24-acetate. Furthermore, Alisol A 24-acetate effectively increased the protein and mRNA expressions of Adiponectin, the phosphorylation of AMPK $\alpha$, CPT1 and ACOX1, whereas decreased SREBP-1C, the phosphorylation of ACC and FAS at

L. Zeng and W. Tang contributed equally to this work.

BenJie Zhou

Department of Pharmacy, Zhujiang Hospital, Southern Medical University, Guangdong, Guangzhou 510282 (PR China)

Tel. +86 02061634549, E-Mail zhoubj163@163.com / zelu2012@126.com
\end{abstract}




\section{Cellular Physiology Cell Physiol Biochem 2016;40:453-464

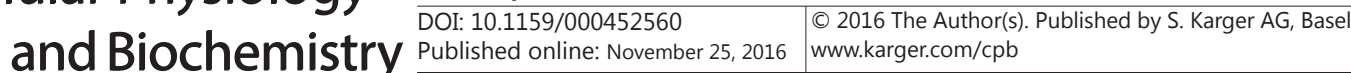 \\ Zeng et al.: Mechanism of Alisol A 24-Acetate Against Hepatic Steatosis}

both protein and mRNA levels. However, there was no significant effect on the protein and mRNA expressions of PPAR $\alpha$ by Alisol A 24-acetate. Conclusions: These results demonstrated that Alisol A 24-acetate effectively ameliorated hepatic steatosis likely through Adiponectin, which activated AMPK $\alpha$ signaling pathways via down-regulating SREBP-1C, ACC, FAS and upregulating CPT1 and ACOX1, and inhibited inflammation. Thereby, Alisol A 24-acetate could be a promising candidate for the treatment of NAFLD.

(C) 2016 The Author(s)

Published by S. Karger AG, Basel

\section{Introduction}

With the improvement of living standard, nonalcoholic fatty liver disease (NAFLD) becomes the most common liver disease, whose incidence is paralleling the increasing numbers of overweight and obese individuals worldwide [1]. It encompasses a spectrum of disease from simple steatosis (triglyceride (TG) over-accumulation) to nonalcoholic steatohepatitis (NASH), characterized by steatosis, hepatocellular damage, and lobular inflammation in individuals without significant alcohol consumption [2]. NAFLD affects 10\% to $24 \%$ of the general population in various countries and the prevalence has even been up to $75 \%$ in obese people [3]. In United States, it translates to approximately 30.1 million obese people affected with steatosis and 8.6 million with steatohepatitis [1]. Liver impairment, ranging from steatosis to cirrhosis, is frequent in cystic fibrosis (CF) patients [4]. Despite the high prevalence of NAFLD and its potential for serious liver injury, the current therapies for NAFLD are limited.

The pathogenesis of NAFLD is not entirely understood, the most widespread and prevailing theory is still the so-called "two-hit" model [5]. The first hit is excessive hepatic fat accumulation; on this basis a large number of adipokines/cytokines (tumor necrosis factor (TNF)- $\alpha$, interleukin (IL)-6, Adiponectin) regulate free fatty acids (FFAs) to induce oxidative stress injury and inflammation is to be the second hit [6-8]. Therefore, hepatic lipid metabolic disorders and inflammation are likely to play important roles in its initiation and development.

NAFLD begins with the accumulation of lipids in the liver. Lipid accumulation in the liver can occur through maladaptations of fatty acid uptake (either through dietary sources or from fat tissue), fatty acid synthesis, fatty acid oxidation, or export of lipids from the liver [9]. Effects on lipid synthesis in NAFLD involve such as the Sterol Regulatory Element Binding Proteins (SREBPs) [10], and fatty acid oxidation, through effects on AMP-activated protein kinase (AMPK), Adiponectin, and peroxisome proliferator-activated receptors (PPARs) [9]. Adiponectin acts through the activation of AMPK and PPAR $\alpha$ pathways [11] and inhibition of SREBP-1c signaling [12]. AMPK activation suppresses the expression of acetyl coenzyme A carboxylase (ACC) and fatty acid synthase (FAS) via down-regulation of SREBP-1c [12]. PPAR $\alpha$ activated by ligand can enhance transcription of acyl coenzyme A oxidase 1 (ACOX1) and carnitine palmitoyltransferase 1 (CPT1)[13]. Adiponectin is inhibited by TNF- $\alpha$, IL- 6 and vice versa [14]. Therefore, Adiponectin has a central role in regulating lipid metabolism and controlling in inflammation.

To expand the number of treatment options for NAFLD, recent studies have focused on identifying active ingredients or herbal extracts that can suppress hepatic lipid accumulation and inflammation. Rhizoma Alismatis, the dried rhizome of Alisma orientale (Sam.) Juz., is a famous Traditional Chinese Medicine which has been widely used for diuretic, hypolipidemic, anti-inflammatory, anti-diabetic purposes, and anti-atherosclerotic etc. for more than 1,000 years in China [15]. As the bioactive "marker compounds" of Rhizoma Alismatis, protostanetype triterpenes, including Alisol A 24-acetate (Fig. 1), which is one of the major active triterpenes isolated from Rhizoma Alismatis, have been determined for the quality control of Rhizoma Alismatis [16]. Alisol A 24-acetate was demonstrated to possess anti-inflammatory and hypocholesterolemic effects $[17,18]$. Therefore, we supposed Alisol A 24-acetate may be effective against hepatic steatosis and inflammation in HepG2 cellular steatosis model, and further addressing its potential mechanisms. 


\section{Cellular Physiology Cell Physiol Biochem 2016;40:453-464

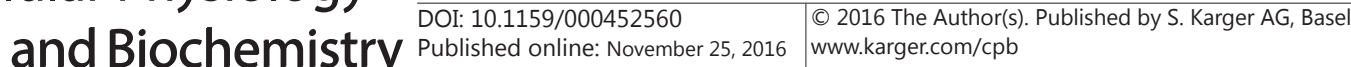 \\ Zeng et al.: Mechanism of Alisol A 24-Acetate Against Hepatic Steatosis}

\section{Materials and Methods}

\section{Reagents}

Alisol A 24-acetate was obtained from Beijing Century Audiocodes Biological Technology Co.Ltd. (Beijing, China). Fenofibrate, Free fatty acids(FFAs) sodium oleate and sodium palmitate, bovine serum albumin(BSA), 3-(4,5-dimethylthiazol-2yl)-2,5diphenyl tetrazolium bromide (MTT) and Oil Red 0 were purchased from Sigma (St. Louis, MO, USA). Triglyceride (TG) assay kit was obtained from Nanjing Jiangcheng Bioengineering Institute (Nanjing, China). BCA protein assay kit and Total protein extraction kit were from Nanjing Kaiji Bioengineering Institute (Nanjing, China). Trizol was obtained from Invitrogen (Carlsbad, USA). Antibodies against sterol regulatory element binding protein 1 (SREBP-1), Adiponectin and ACOX1 were purchased from Abcam (Cambridge, MA). AMPK and ACC Antibody Sampler kits, and antibodies against FAS and CPT1 were purchased from Cell Signaling Technology, Inc (Beverly, Massachusetts, USA). RPMI 1640 and fetal bovine serum (FBS) were purchased from Gibco (USA). Penicillin and streptomycin and $0.25 \%$ pancreatin were purchased from Genom (Hangzhou, China). All other reagents were of analytical grade.

\section{Cell culture}

Hepatocellular carcinoma cell line HepG2 cells were obtained from China Cell Culture Center (Shanghai, China). HepG2 cells were cultured in RPMI 1640 supplemented with 10\% FBS, $100 \mathrm{U} / \mathrm{ml}$ penicillin, and 100 $\mu \mathrm{g} / \mathrm{ml}$ streptomycin in a humidified incubator under $95 \%$ air and $5 \% \mathrm{CO}_{2}$ at $37^{\circ} \mathrm{C}$.

\section{Cell viability for selected action concentration of Alisol A 24-acetate}

Alisol A 24-acetate was dissolved in DMSO as $100 \mathrm{mM}$ storage concentrate, repackaged and cryopreserved, which was diluted with serum free medium into the required concentration before use. HepG2 cells in $100 \mu \mathrm{L}$ medium were seeded in 96-well plates at $1 \times 10^{4}$ cells per well, and wells without cells act Blank group. $24 \mathrm{~h}$ after plating, the medium was discarded and RPMI 1640 containing Alisol A 24-acetate at various concentrations $(0,2.5,5,10,20,50,100 \mu \mathrm{M})$ was added. After another $24 \mathrm{~h}$, the soulutions were replaced with $100 \mu \mathrm{L}$ of fresh medium and $10 \mu \mathrm{L}$ of MTT assay reagents $(5 \mathrm{mg} / \mathrm{ml})$ for $4 \mathrm{~h}$ of incubation at $37^{\circ} \mathrm{C}$ then the resulting formazan was solubilized in $150 \mu \mathrm{L}$ dimethyl sulfoxide (DMSO) and dissolved oscillatorily at room temperature for $10 \mathrm{~min}$. The absorbance was measured at $570 \mathrm{~nm}$ on a Bio-Rad Model 680 microplate reader (California, USA).

Experimental design for treatment with the Alisol A 24-acetate in HepG2 cellular steatosis

To induce cellular steatosis, HepG2 cells at $80 \%$ confluence were stimulated by a mixture of 1 mM FFA (oleate:palmitate=2:1) in RPMI 1640 containing 1\% BSA for $24 \mathrm{~h}[19,20]$. The cells in FFA+A and FFA+F groups were incubated with $1 \mathrm{mM}$ FFA plus $10 \mu \mathrm{M}$ Alisol A 24-acetate (according to the result of above) and $10 \mu \mathrm{M}$ Fenofibrate [21] respectively for $24 \mathrm{~h}$ for treating with preventive administration in the medium. "FFA group" was exposed to the 1 mM FFA in media in the absence of drug and "Control group" was treated with FFA-free medium. Each group consisted of three replicates.

\section{Oil red $O$ staining}

HepG2 cells ( $2.5 \times 10^{5}$ /well) were plated in 12-well plates and administrated according to the experimental design described in above. The cells in the different groups were washed with phosphate buffer saline (PBS), then fixed with 4\% paraformaldehyde for $30 \mathrm{~min}$ and stained with a freshly prepared working solution of Oil Red $\mathrm{O}$ for $50 \mathrm{~min}$ at room temperature followed by being counterstained with hemaoxylin before microscopic observation (Olympus Corporation, Tokyo, Japan). To quantify the Oil Red 0 content, $200 \mu \mathrm{L}$ isopropanol was added to each sample and shaken at room temperature for $15 \mathrm{~min}$. The absorbance of each isopropanol-extracted sample was read with a spectrophotometer at $490 \mathrm{~nm}$.

\section{Measurement of TG content}

TG content was measured using a commercial kit in cell lysates (from $5 \times 10^{5} / 60 \mathrm{~mm}$ Petri dishes) prepared on ice using 2\% TritonX-100 (Amresco, USA) according to the manufacturer's instruction. The 


\section{Cellular Physiology Cell Physiol Biochem 2016;40:453-464

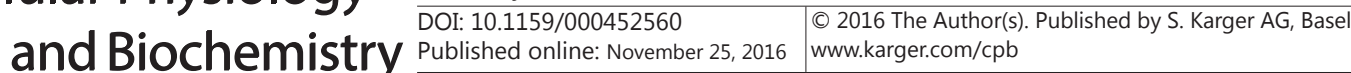 \\ Zeng et al.: Mechanism of Alisol A 24-Acetate Against Hepatic Steatosis}

Table 1. Gene-special primers used for Read-time PCR

\begin{tabular}{|c|c|c|c|}
\hline Gene & Sequences & PCR Product & Gen Bank No. \\
\hline \multirow[t]{2}{*}{ Human Adiponectin } & 5'- GCATTCAGTGTGGGATTGGAGAC-3'(Forward) & $104 \mathrm{bp}$ & NM_001177800 \\
\hline & 5'-CCAGTGGAGCCATCATAGTGGTT-3'(Reverse) & & \\
\hline \multirow[t]{2}{*}{ Human AMPK } & 5'-CСАСАТСТССТССАGGTCATCC-3' (Forward) & $135 \mathrm{bp}$ & NM_006253 \\
\hline & 5'-GCTGAGCACCATCACTCCATCC-3' (Reverse) & & \\
\hline \multirow[t]{2}{*}{ Human SREBP-1c } & 5'-CACTGGTCGTAGATGCGGAGAA-3' (Forward) & $139 \mathrm{bp}$ & NM_001005291 \\
\hline & 5'-TCATTGATGGAGGAGCGGTAGC-3' (Reverse) & & \\
\hline \multirow[t]{2}{*}{ Human ACC } & 5'-CTGGCTGGCTGGACAGACTGAT-3' (Forward) & $115 \mathrm{bp}$ & NM_198834 \\
\hline & 5'-ACGCTATTCCGCAGGCTCACA-3' (Reverse) & & \\
\hline \multirow[t]{2}{*}{ Human FAS } & 5'-AGGACATGGCTTAGAAGTGGAA-3' (Forward) & 166bp & NM_000043.4 \\
\hline & 5'-CTTGGTGTTGCTGGTGAGTG-3' (Reverse) & & \\
\hline \multirow[t]{2}{*}{ Human PPAR $\alpha$} & 5'-AGCAAGGAAGGGTTGTGGCAAA-3' (Forward) & $130 \mathrm{bp}$ & NM_001001928 \\
\hline & 5'-ATGGACTCGGAAGCAGGAAGGT-3' (Reverse) & & \\
\hline \multirow[t]{2}{*}{ Human CPT1 } & 5'-TGAGCACGGCAAGATGAGTC-3' (Forward) & $104 \mathrm{bp}$ & NM_001876.3 \\
\hline & 5'-GAGGCAGCGATGTCTGGAAG-3' (Reverse) & & \\
\hline \multirow[t]{2}{*}{ Human ACOX1 } & 5'-GACCTGAGTGAACTGCCTGAG-3' (Forward) & $106 \mathrm{bp}$ & NM_004035.6 \\
\hline & 5'-CACCACAAGCCATCCGACAT-3' (Forward) & & \\
\hline \multirow[t]{2}{*}{ Human 18s } & 5'-CCTGGATACCGCAGCTAGGA-3' (Forward) & $112 \mathrm{bp}$ & NR_003286 \\
\hline & 5'-GCGGCGCAATACGAATGCCCC-3' (Reverse) & & \\
\hline
\end{tabular}

protein concentrations were determined with a BCA Protein Assay Kit. The result of TG was expressed as $\mathrm{mM}$ TG per g protein (mM/g protein).

Cytokine assay

Adiponectin and the anti-inflammatory cytokines TNF- $\alpha$ and IL-6 in HepG2 cells supernatant (from 1 x $10^{5} / 24$-well plates) were measured using commercially available enzyme linked immunosorbant assay (ELISA) (Multisciences, Hangzhou, China) following the user guide provided with kit.

\section{Real-time PCR}

Total cellular RNA, from cells ( $3 \times 10^{5}$ /well) seeded in 6-well plates, was extracted using Trizol Reagent (Invitrogen, Carlsbad, USA). The purified RNA was examined by electrophoresis. Total RNA (1.5 $\mu \mathrm{g})$ was reverse transcribed using an oligo $(\mathrm{dt})_{18}$ primer to produce cDNA. RT-PCR was used to measure the mRNA expression levels of AMPK, SREBP-1c, ACC, FAS, PPAR $\alpha$, CPT1, ACOX1, Adiponectin and H-18s. Real-time PCR was performed on cDNA samples and primers with SYBR ${ }^{\circledR}$ Premix Ex Taq ${ }^{\text {TM }}$ (Tli RNaseH Plus) (TAKARA, Japan). The sequences of the primers were showed in Table 1 . The amplification conditions were: $95^{\circ} \mathrm{C}$ for $5 \mathrm{~min}$ for initial denaturation, followed by 45 amplification cycles of denaturation at $95^{\circ} \mathrm{C}$ for $3 \mathrm{~s}$ and combined annealing and extension at 60 for $34 \mathrm{~s}$.

\section{Western blotting}

Cell lysates $\left(2 \times 10^{6}\right.$ cells $/ 25 \mathrm{~cm}^{2}$ cell culture flask) were prepared on ice using RIPA buffer (Total protein extraction kit). The protein concentrations were determined with the BCA Protein Assay Kit. Equal amounts of protein were separated by 6-15\% SDS-PAGE, and transferred to polyvinylidene difluoride (PVDF) membranes (Millipore, Billerica, USA). The membranes were blocked with 5\% nonfat skim milk for $3 \mathrm{~h}$ at room temperature and immunoblotted with polyclonal primary antibodies directed against Adiponectin (1:1000), SREBP-1 (1:1000), PPAR $\alpha$ (1:1000), CPT1 (1:1000), ACOX1 (1:1000), AMPK $\alpha$ (1:1000), p-AMPK $\alpha$ (1:1000), ACC (1:1000), p-ACC (1:1000), FAS (1:1000) and glyceraldehyde 3-phosphate dehydrogenase (GADPH, the internal control) (1:1000). The immunoblots were incubated with peroxidase-conjugated secondary antibodies (diluted $1: 5000$ ) at $25^{\circ} \mathrm{C}$ for $1 \mathrm{~h}$. The proteins were detected with a chemiluminescent substrate (ECL, Amersham, USA), and exposed to X-ray for detection. Image J software was used for the densitometric analysis of the bands.

Statistical analysis

All experimental data were expressed as means \pm S.D. Statistical analysis was performed with SPSS 13.0 software and an analysis of variance (ANOVA) was used to compare means in different groups followed by a 


\section{Cellular Physiology Cell Physiol Biochem 2016;40:453-464

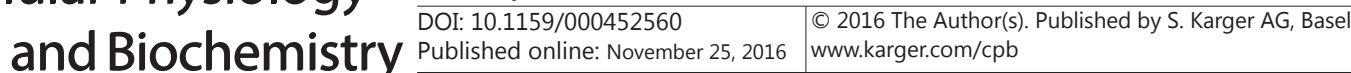 \\ Zeng et al.: Mechanism of Alisol A 24-Acetate Against Hepatic Steatosis}

post-hoc Dunnett's or Bonferroni's multiple comparisons test, where a P value less than 0.05 was considered significant. All assays were conducted in duplicate and each experiment was performed at least three times.

\section{Results}

Cell viability of Alisol A 24-acetate

Alisol A 24-acetate reduced HepG2 cells viability in a dose-dependent manner. (Fig. 2). During exposure to Alisol A 24-acetate for $24 \mathrm{~h}$, HepG2 cells viability was reduced at concentrations from $2.5 \mu \mathrm{M}$ to $100 \mu \mathrm{M}$. Alisol A 24-acetate caused greatly significant inhibition of cell proliferation at concentrations above $10 \mu \mathrm{M}$, whose cytotoxicity reached $23.85 \%$ at concentration $20 \mu \mathrm{M}$. The result was consistent with the previous literature [22]. Hence, $10 \mu \mathrm{M}$ Alisol A 24-acetate for an exposure time of $24 \mathrm{~h}$ was selected for its action concentration.

\section{Effect of Alisol A 24-acetate on lipid accumulation in FFA induced hepatic steatosis}

Oil Red 0 staining (Fig. 3A) showed that lipid droplets accumulated significantly $(\mathrm{p}<0.01)$ in the HepG2 cells cytoplasm at 1 mM FFA compared with the Control group, Alisol A 24-acetate and Fenofibrate significantly reduced the numbers of the lipid droplets compared with the FFA group. Furthermore, as shown in Fig. 3B and C, the Oil Red O lipid content and intracellular TG content were increased significantly in the FFA groups compared with the Control groups $(p<0.01)$, and decreased significantly in the FFA+A and FFA+F groups $(\mathrm{p}<0.05, \mathrm{p}<0.01$ versus the FFA group).

Fig. 2. Dose-dependent effect of Alisol A 24-acetate on viability of HepG2 cells. HepG2 cells were incubated with or without Alisol A 24-acetate at different concentrations and cell viability was measured by MTT assay. Alisol A 24-acetate concentration (>10 $\mu \mathrm{M}$ ) significantly inhibited cell proliferation for $24 \mathrm{~h}$. Data are expressed as means $\pm S D(n=3) .{ }^{\# \#} \mathrm{P}<0.01$ vs. the control (without Alisol A 24-acetate).

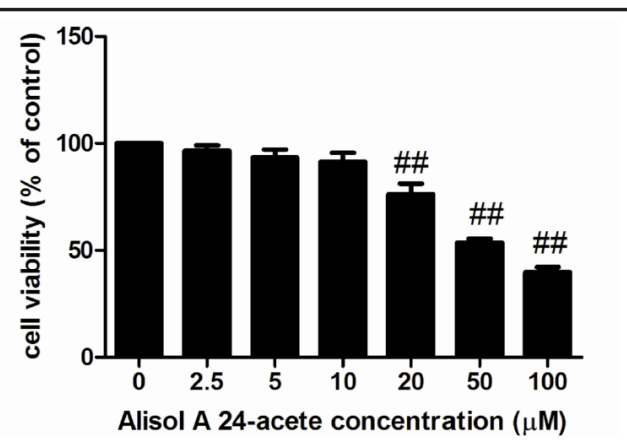

Fig. 3. Effect of Alisol A 24-acetate on lipid accumulation in FFA induced hepatic steatosis. (A) Oil Red 0 staining (magnification $\times 400$ ). (B) Oil Red O colorimetric assay. (C) Intracellular TG content. Results are expressed as means \pm SD. ${ }^{\# \#} \mathrm{p}<0.01$ compared with the control groups; ${ }^{*} \mathrm{p}<0.05$, ${ }^{* *} \mathrm{p}<0.01$ compared with the FFA groups. Con, control group; FFA, FFA groups; FFA+A, FFA + Alisol A 24-acetate (10 $\mu \mathrm{M})$; FFA+F, FFA + Fenofibrate $(10 \mu \mathrm{M})$.

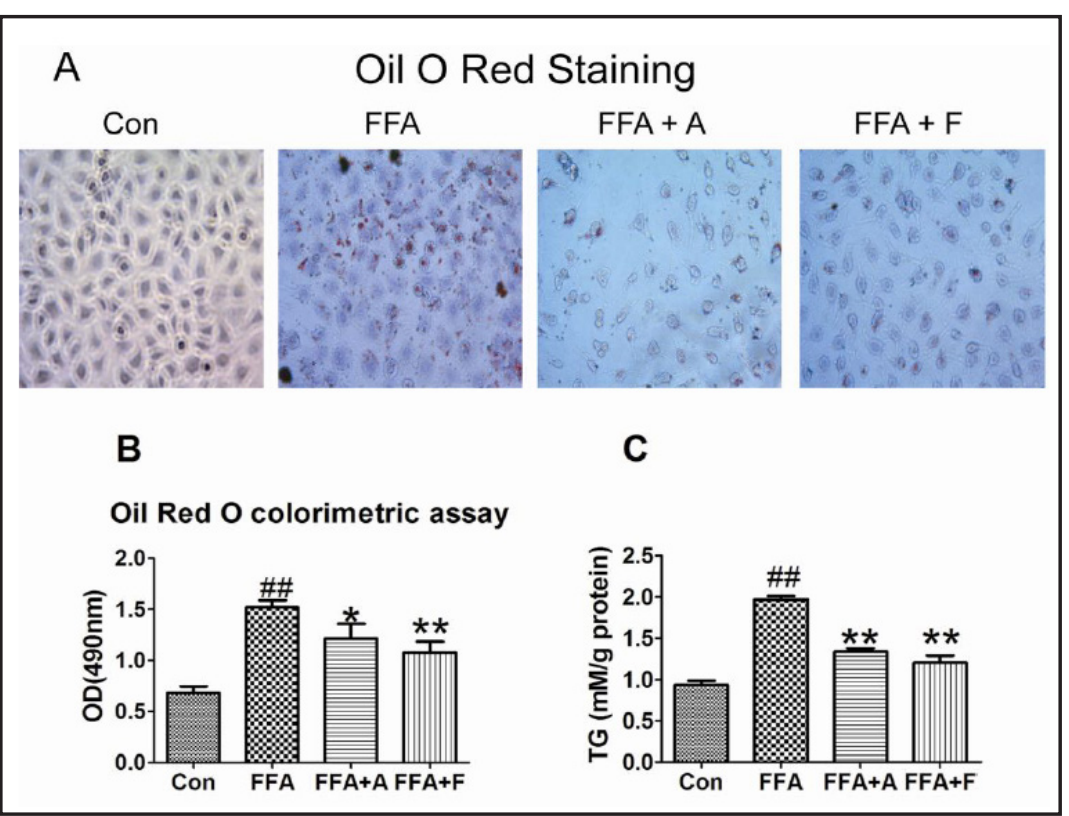

\section{KARGER}


Effect of Alisol A 24-acetate on inflammatory cytokines in FFA induced hepatic steatosis As shown in Fig. 4A and $B$, inflammatory cytokines TNF- $\alpha$ and IL-6 levels increased significantly in the FFA groups compared with those in the Control groups $(\mathrm{p}<0.01)$, and significantly reverted by Alisol A 24-acetate $(\mathrm{p}<0.01)$. However, the results showed that Fenfibrate had no significant inhibition of TNF- $\alpha$ and IL-6 levels $(\mathrm{p}>0.05)$.

Effect of Alisol A 24-acetate on the expression of Adiponectin in FFA induced hepatic steatosis The Elisa result (Fig. $5 \mathrm{~A})$ showed the expression of Adiponectin in the FFA group was much lower than that in the Control group $(\mathrm{p}<0.01)$. Whereas, Alisol A 24-acetate up-regulated the expression of Adiponectin significantly compared with the FFA group $(\mathrm{p}<0.01)$ as well as the Adiponectin mRNA expression (Fig. 5B).

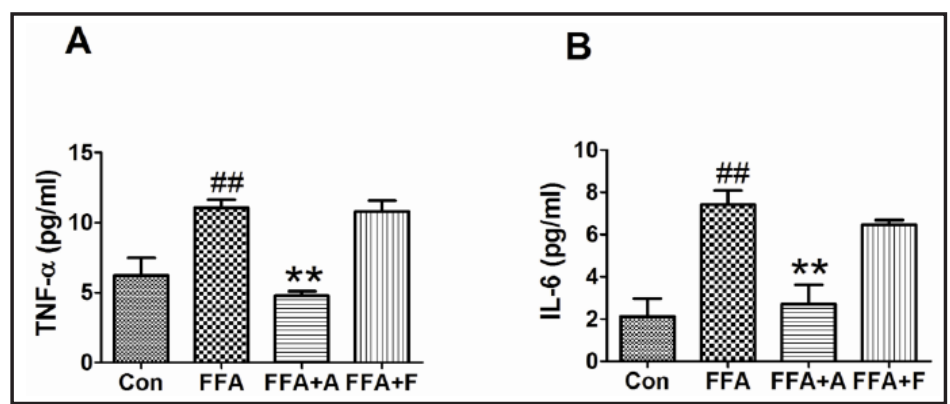

Fig. 4. Effect of Alisol A 24-acetate on inflammatory cytokines (A) TNF- $\alpha$ and (B) IL-6 in FFA induced hepatic steatosis. Results are expressed as means \pm SD. ${ }^{\# \#} \mathrm{p}<0.01$ compared with the control groups; ${ }^{* *} \mathrm{p}<0.01$ compared with the FFA groups. Con, control group; FFA, FFA groups; FFA+A, FFA + Alisol A 24-acetate $(10 \mu \mathrm{M})$; FFA+F, FFA + Fenofibrate $(10 \mu \mathrm{M})$.

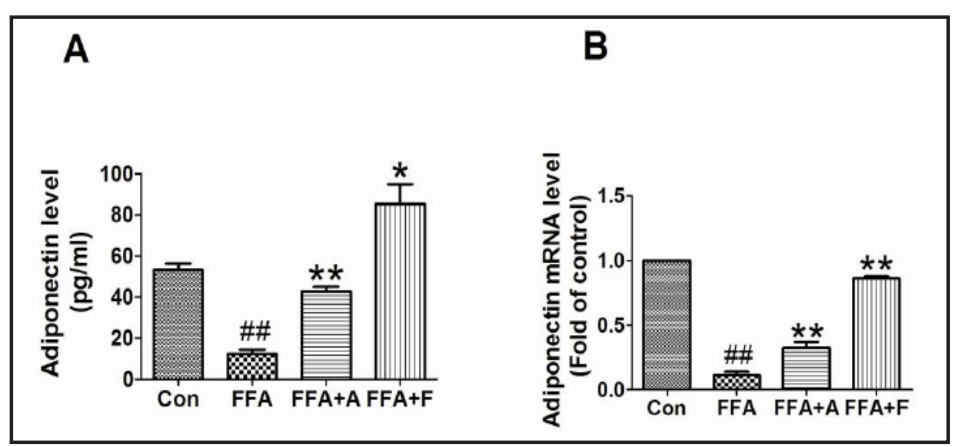

Fig. 5. Effect of Alisol A 24-acetate on the expression of Adiponectin in FFA induced hepatic steatosis. (A) Adiponectin expression determined by Elisa. (B) Adiponectin mRNA expression determined by RT-PCR. Results are expressed as means \pm SD. ${ }^{\# \#} \mathrm{p}<0.01$ compared with the control groups; * $<<0.05,{ }^{* *} \mathrm{p}<0.01$ compared with the FFA groups. Con, control group; FFA, FFA groups; FFA+A, FFA + Alisol A 24-acetate $(10 \mu \mathrm{M})$; FFA+F, FFA + Fenofibrate $(10 \mu \mathrm{M})$.

Effect of Alisol A 24-acetate on AMPK-SREBP-1-ACC-FAS pathways in FFA induced hepatic steatosis

AMPK $\alpha$ phosphorylation suppresses lipogenic gene expression involved in triglyceride synthesis and accumulation (such as ACC and FAS) via down-regulating the expression of the transcription factor SREBP-1c. As showed in Fig. 6A-D, the protein level of p-AMPK $\alpha$ decreased significantly while the protein levels of p-ACC, FAS and SREBP-1 increased significantly in the FFA groups compared with the Control groups $(\mathrm{p}<0.01)$. Howerver, Alisol A 24-acetate significantly up-regulated p-AMPK $\alpha$ level and decreased p-ACC, FAS and SREBP-1 levels $(\mathrm{p}<0.01)$. The levels of AMPK mRNA, ACC mRNA, FAS mRNA and SREBP-1c mRNA showed similar results (Fig. 7A-D).

Effect of Alisol A 24-acetate on PPAR $\alpha$-CPT1-ACOX1 pathways in FFA induced hepatic steatosis

As showed in Fig. 8A-C and Fig. 9A-C, compared with the control group, the protein and mRNA levels of PPAR $\alpha, C P T 1$ and ACOX1 in the FFA group were significantly decreased $(p<0.05$, $p<0.01)$. Alisol A 24-acetate had no significant effect on PPAR $\alpha$ expression ( $>>0.05)$. while the CPT1 and ACOX1 expressions were significantly increased in Alisol A 24-acetate group $(\mathrm{p}<0.05)$. 
Fig. 6. Effect of Alisol A 24-acetate on AMPK relative protein content in FFA induced hepatic steatosis. Protein content of (A) p-AMPK $\alpha$, (B) SREBP-1, (C) p-ACC, (D) FAS. Results are expressed as means \pm SD. ${ }^{\# \#} \mathrm{p}<0.01$ compared with the control groups; $* \mathrm{p}<0.05$, ${ }^{* *} \mathrm{p}<0.01$ compared with the FFA groups. Con, control group; FFA, FFA groups; FFA+A, FFA + Alisol A 24-acetate $(10 \mu \mathrm{M})$; FFA+F, FFA + Fenofibrate (10 $\mu \mathrm{M})$.

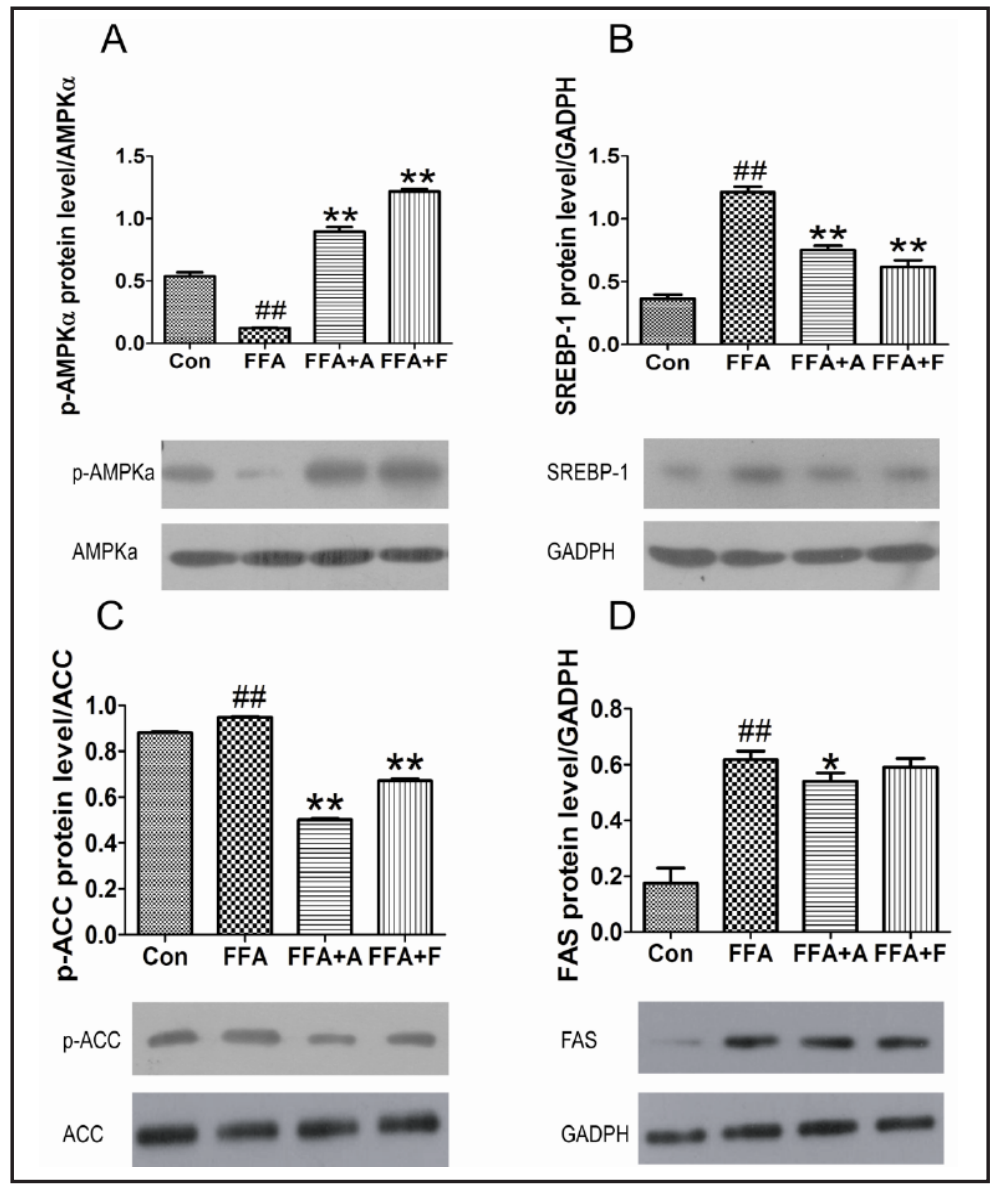

Fig. 7. Effect of Alisol A 24-acetate on AMPK relative mRNA levels in FFA induced hepatic steatosis. mRNA level of (A) AMPK, (B) SREBP-1c, (C) ACC, (D) FAS. Results are expressed as means \pm SD. ${ }^{\# \#} \mathrm{p}<0.01$ compared with the control groups; ${ }^{*} \mathrm{p}<0.05,{ }^{* *} \mathrm{p}<0.01 \quad$ compared with the FFA groups. Con, control group; FFA, FFA groups; $\mathrm{FFA}+\mathrm{A}, \mathrm{FFA}+$ Alisol A 24-acetate $(10 \mu \mathrm{M}) ; \mathrm{FFA}+\mathrm{F}$, FFA + Fenofibrate $(10 \mu \mathrm{M})$.

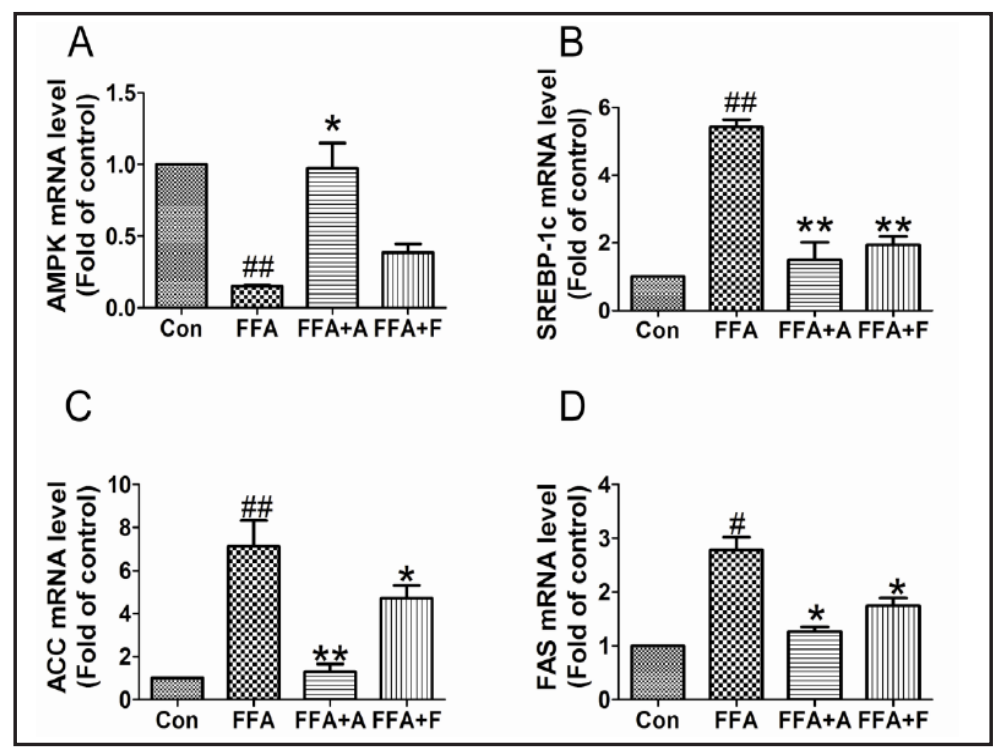

\section{Discussion}

Alisol A 24-acetate is the major component of Alismatis rhizome. Previous studies have demonstrated anti-inflammatory and hypocholesterolemic effects of Alisol A 24-acetate [17, 18], however, the mechanism of action on hepatic steatosis has never been reported. The present study suggests the possible pathways that Alisol A 24-acetate ameliorated hepatic steatosis. 


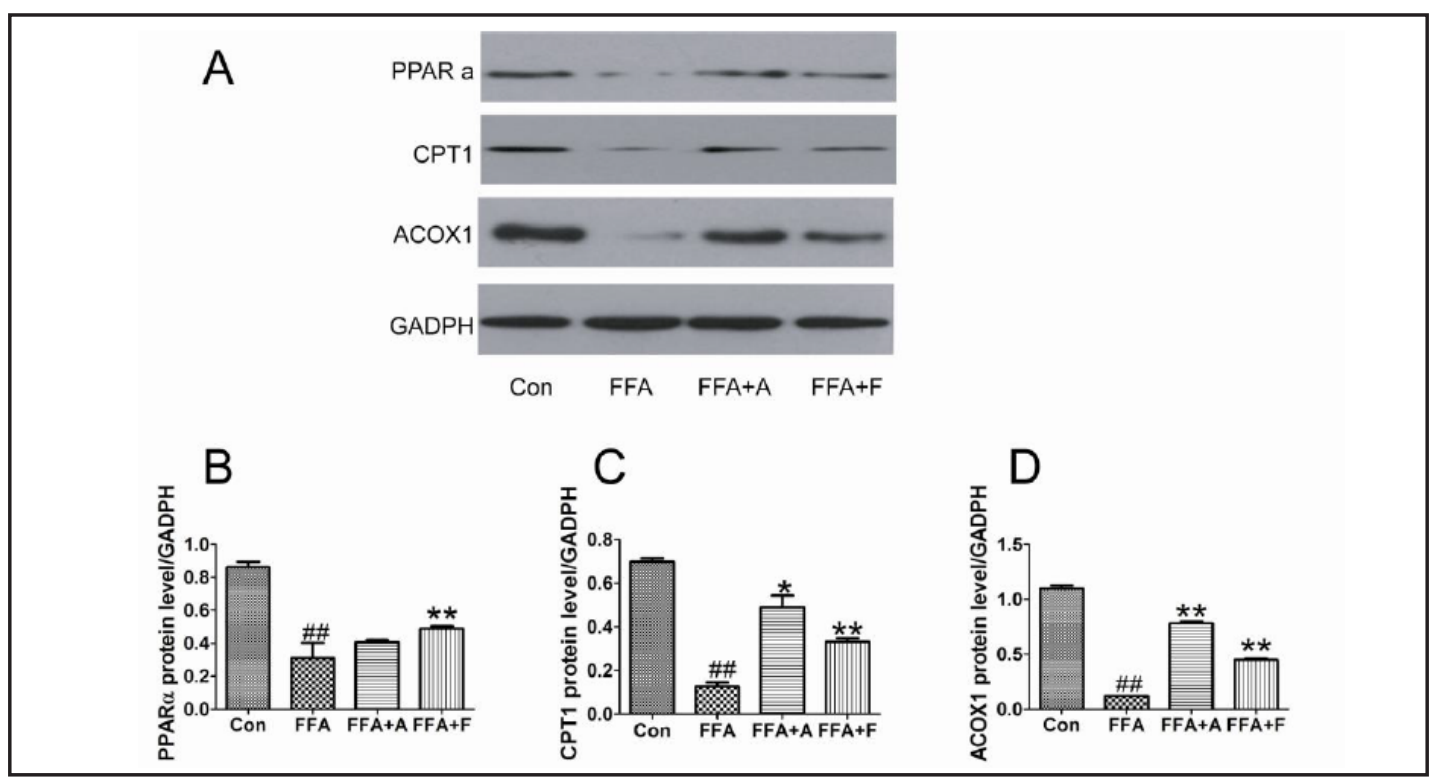

Fig. 8. Effect of Alisol A 24-acetate on PPAR $\alpha$ relative protein content in FFA induced hepatic steatosis. (A) Western blot. Protein content of (B) PPAR $\alpha$, (C) CPT1, (D) ACOX1. Results are expressed as means \pm SD. ${ }^{\# \#} \mathrm{p}<0.01$ compared with the control groups; ${ }^{*} \mathrm{p}<0.05,{ }^{* *} \mathrm{p}<0.01$ compared with the FFA groups. Con, control group; FFA, FFA groups; FFA+A, FFA + Alisol A 24-acetate $(10 \mu \mathrm{M})$; FFA+F, FFA + Fenofibrate $(10 \mu \mathrm{M})$.

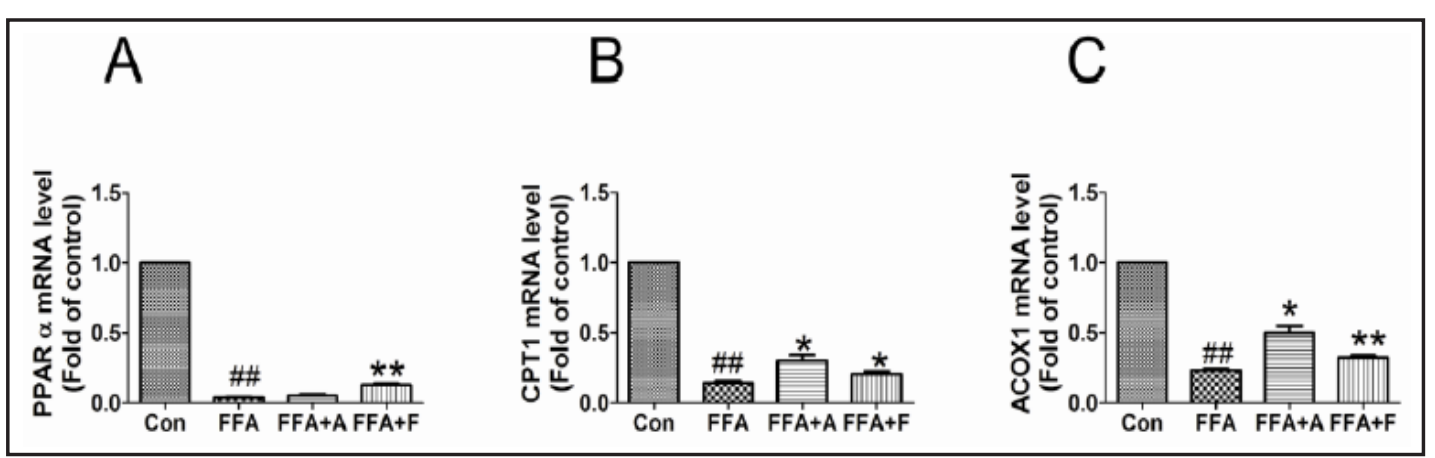

Fig. 9. Effect of Alisol A 24-acetate on PPAR $\alpha$ relative mRNA levels in FFA induced hepatic steatosis. mRNA level of (A) PPAR $\alpha,(B)$ CPT1, (C) ACOX1. Results are expressed as means \pm SD. ${ }^{\# \#} \mathrm{p}<0.01$ compared with the control groups; ${ }^{*} \mathrm{p}<0.05,{ }^{* *} \mathrm{p}<0.01$ compared with the FFA groups. Con, control group; FFA, FFA groups; $\mathrm{FFA}+\mathrm{A}, \mathrm{FFA}+$ Alisol A 24-acetate $(10 \mu \mathrm{M}) ; \mathrm{FFA}+\mathrm{F}, \mathrm{FFA}+$ Fenofibrate $(10 \mu \mathrm{M})$.

Hepatic steatosis results from increased fatty acid influx to the hepatocytes and reduced lipid oxidation [23]. In the hepatocyte, the FFA may be converted to TG for storage or undergo oxidation, and excess TG may be stored in lipid droplets [24]. Increased fatty acid influx into the hepatocytes may have resulted in the generation of reactive oxygen species (ROS) to induce oxidative stress by the accumulation of free fatty acids in mitochondria due to saturation of mitochondrial $\beta$-oxidation [23]. In our study, HepG 2 cells were induced by $1 \mathrm{mM}$ FFA (oleate : palmitate $=2: 1$ ) to mimic the influx of excess FFAs into hepatocytes, giving rise to hepatic steatosis $[19,20]$. Our data showed that the number of lipid droplets and the contents of the Oil Red O lipid and TG increased significantly in the FFA-induced HepG2 cells, indicating that the hepatic steatosis model in vitro had been successfully established. Alisol A 24-acetate significantly reduced the accumulation of lipid droplets, the contents of the Oil Red 0 lipid and intracellular TG (Fig. 3). Furthermore, excessive FFA also causes oxidative stress to produce inflammation in liver [25]. TNF- $\alpha$ and IL- 6 are the major pro-inflammatory 


\section{Cellular Physiology Cell Physiol Biochem 2016;40:453-464

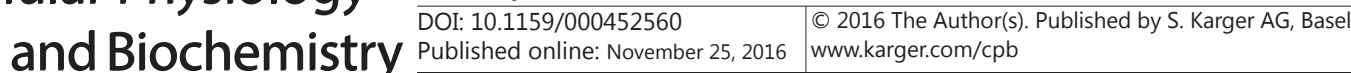 \\ Zeng et al.: Mechanism of Alisol A 24-Acetate Against Hepatic Steatosis}

cytokines in NAFLD and are thought to cause the NASH and fibrosis. It is suggested that TNF- $\alpha$ and IL- 6 are the key cytokines in the development of hepatic steatosis[26]. Our results showed that TNF- $\alpha$ and IL-6 levels were significantly increased in FFA group, and were remarkably decreased in Alisol A 24-acetate group, indicating that Alisol A 24-acetate possesses strong anti-inflammatory effect (Fig. 4).

The pathophysiology of NAFLD and NASH has many links with the hepatic lipid metabolism, which is related with Adiponectin, AMPK $\alpha$, SREBP-1c, ACC, FAS, and PPAR $\alpha$, CPT1, ACOX1 pathways $[9,27,28]$. Adiponectin, a cytokine secreted by adipose tissue or adipokine, which functions in regulating energy balance and fat metabolism, and is anti-steatotic and anti-inflammatory [7, 11]. Adiponectin knockout mice developed hepatic steatosis [29], and patients with both steatosis and NASH have decreased serum levels of Adiponectin [30, 31]. Adiponectin suppresses inflammation by inhibiting pro-inflammatory mediators such as TNF- $\alpha$ and IL-6 [32], and inversely TNF- $\alpha$ and IL- 6 can inhibit the expression of Adiponectin [33]. Therefore, Adiponectin, TNF- $\alpha$ and IL- 6 have central roles in regulating glucose and lipid metabolism and controlling inflammation, and Adiponectin was negatively correlated with the degree of inflammation. In our study, we obtained a low Adiponectin level in the FFA group, and Alisol A 24-acetate significantly increased the expression of Adiponectin (Fig. 5), associated with the low levels of TNF- $\alpha$ and IL-6. These results indicate that the preventive effect of Alisol A 24-acetate on hepatic steatosis might be partly attributable to the up-regulated expression of Adiponectin and inhibition of TNF- $\alpha$ and IL- 6 levels.

Adiponectin achieves its function in the liver likely via activating AMPK and PPAR $\alpha$ pathways $[34,35]$. AMPK is a key player in regulating energy metabolism and fatty acid oxidation, and AMPK $\alpha$ is the major subunit [36]. AMPK $\alpha$ phosphorylation mediates suppression of lipogenic gene expression involved in triglyceride synthesis and accumulation (such as ACC and FAS) via decreasing the actions of transcriptional factors SREBP-1c [37]. Metformin activated AMPK in hepatocytes, reducing ACC activity, inducing fatty acid oxidation and inhibiting SREBP-1c expression, thus preventing the development of hepatic steatosis [38]. Baicalin was able to decrease fatty liver diseases possibly via AMPK/ACC pathway in high fat diet animal model [39]. PPAR $\alpha$ is a nuclear receptor highly expressed in the liver, which is able to exert its transcriptional effects on genes involved in fatty acid oxidation, uptake as well as inflammation $[40,41]$. PPAR $\alpha$ activated by ligand can enhance transcription of ACOX1 and CPT1. CPT1 regulates uptake of fatty acid and is considered the rate-limiting enzyme in fatty acid oxidation in the mitochondria. ACOX1 is the key enzyme of peroxisomal $\beta$ - oxidation, and lack of the gene results in hepatocytes that can't oxidize very long chain fatty acids and causes hepatic steatosis. PPAR $\alpha$ agonist up-regulates the expression of CPT1 [42] and inhibits TNF- $\alpha$ and IL-6 levels [43, 44]. AMPK activation increases fatty acid oxidation likely by activating PPAR $\alpha$ [45] and CPT1 [46]. Therefore, AMPK and PPAR $\alpha$ are two critical regulators of hepatic lipid metabolism and may be therapeutic targets in the treatment of NAFLD. In this study, it seems plausible that Alisol A 24-acetate activates AMPK $\alpha$ phosphorylation and down-regulates SREBP-1c, ACC, FAS expressions, and up-regulates CPT1 and ACOX1 expressions. PPAR $\alpha$ expression isn't significantly increased by Alisol A 24-acetate, which might show that it requires very little change in PPAR $\alpha$ to alter expression of CPT1 and ACOX1 genes that are likely through AMPK $\alpha$. It indicates that Alisol A 24-acetate decreases fatty acid synthesis and increases fatty acid $\beta$-oxidation possibly through AMPKSREBP-1c-ACC-FAS-CPT1-ACOX1 pathways to prevent hepatic steatosis (Fig.6 and 9).

\section{Conclusion}

In conclusion, the results show that Alisol A 24-acetate has effects on abnormal lipid metabolism. Alisol A 24-acetate might not only reduce lipid accumulation but also exert an effect on inflammation. Furthermore, Alisol A 24-acetate might prevent hepatic steatosis by up-regulating Adiponectin expression, which activates the AMPK signaling pathway thereby down-regulating SREBP-1c, ACC, FAS expressions and increasing CPT1, ACOX1 expressions. 


\section{Cellular Physiology Cell Physiol Biochem 2016:40:453-464

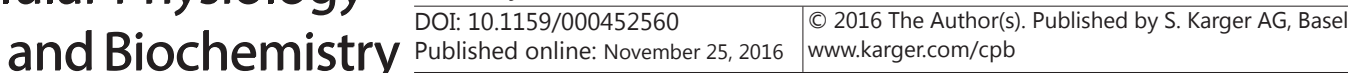 \\ Zeng et al.: Mechanism of Alisol A 24-Acetate Against Hepatic Steatosis}

Therefore, Alisol A 24-acetate could be developed as potential therapeutic treatment for NAFLD.

\section{Acknowledgments}

This study was supported by grants from the Natural Science Foundation of China (No. 81274160), the Natural Science Foundation of Guangdong Province (No. S2012010009380).

\section{Disclosure Statement}

The authors declare that there are no conflicts of interest.

\section{References}

1 Yan E, Durazo F, Tong M, Hong K: Nonalcoholic fatty liver disease: Pathogenesis, identification, progression, and management. Nutr Rev 2007;65:376-384.

2 Durazzo M, Belci P, Collo A, Grisoglio E, Bo S: Focus on therapeutic strategies of nonalcoholic Fatty liver disease. Int J Hepatol 2012;2012:464706.

3 Miele L, Forgione A, Hernandez AP, Gabrieli ML, Vero V, Di Rocco P, Greco AV, Gasbarrini G, Gasbarrini A, Grieco A: The natural history and risk factors for progression of non-alcoholic fatty liver disease and steatohepatitis. Eur Rev Med Pharmacol Sci 2005;9:273-277.

4 Grothe J, Riethmuller J, Tschurtz SM, Raith M, Pynn CJ, Stoll D, Bernhard W: Plasma phosphatidylcholine alterations in cystic fibrosis patients: Impaired metabolism and correlation with lung function and inflammation. Cell Physiol Biochem 2015;35:1437-1453.

5 Day CP, James OF: Steatohepatitis: A tale of two "hits"? Gastroenterology 1998;114:842-845.

6 Tiniakos DG, Vos MB, Brunt EM: Nonalcoholic fatty liver disease: Pathology and pathogenesis. Annu Rev Pathol 2010;5:145-171.

7 Tilg H: Adipocytokines in nonalcoholic fatty liver disease: Key players regulating steatosis, inflammation and fibrosis. Curr Pharm Des 2010;16:1893-1895.

8 Orlik B, Handzlik G, Olszanecka-Glinianowicz M: [the role of adipokines and insulin resistance in the pathogenesis of nonalcoholic fatty liver disease]. Postepy Hig Med Dosw (Online) 2010;64:212-219.

9 Sozio MS, Liangpunsakul S, Crabb D: The role of lipid metabolism in the pathogenesis of alcoholic and nonalcoholic hepatic steatosis. Semin Liver Dis 2010;30:378-390.

10 Bitter A, Nussler AK, Thasler WE, Klein K, Zanger UM, Schwab M, Burk O: Human sterol regulatory elementbinding protein $1 \mathrm{a}$ contributes significantly to hepatic lipogenic gene expression. Cell Physiol Biochem 2015;35:803-815.

11 Polyzos SA, Kountouras J, Zavos C, Tsiaousi E: The role of adiponectin in the pathogenesis and treatment of non-alcoholic fatty liver disease. Diabetes Obes Metab 2010;12:365-383.

12 Zeng L, Tang WJ, Yin JJ, Zhou BJ: Signal transductions and nonalcoholic fatty liver: A mini-review. Int J Clin Exp Med 2014;7:1624-1631.

13 Chitturi S, Abeygunasekera S, Farrell GC, Holmes-Walker J, Hui JM, Fung C, Karim R, Lin R, Samarasinghe D, Liddle C, Weltman M, George J: NASH and insulin resistance: Insulin hypersecretion and specific association with the insulin resistance syndrome. Hepatology 2002;35:373-379.

14 Musso G, Gambino R, Cassader M: Non-alcoholic fatty liver disease from pathogenesis to management: An update. Obes Rev 2010;11:430-445.

15 Yu Y, Li Q, Bi K, Xie P, Yang G, Chen X: A sensitive liquid chromatography-mass spectrometry method for simultaneous determination of alisol a and alisol a 24-acetate from Alisma orientale (Sam.) Juz. In rat plasma. Anal Bioanal Chem 2011;399:1363-1369.

16 Makabel B, Zhao Y, Wang B, Bai Y, Zhang Q, Wu L, Lv Y: Stability and structure studies on alisol a 24-acetate. Chem Pharm Bull (Tokyo) 2008;56:41-45. 


\section{Cellular Physiology Cell Physiol Biochem 2016;40:453-464 and Biochemistry \begin{tabular}{l|l} 
DOI: 10.1159/000452560 & (c) 2016 The Author(s). Published by S. Karger AG, Basel \\
www.karger.com/cpb
\end{tabular} \\ Zeng et al.: Mechanism of Alisol A 24-Acetate Against Hepatic Steatosis}

17 Matsuda H, Tomohiro N, Yoshikawa M, Kubo M: Studies on Alismatis Rhizoma. II. Anti-complementary activities of methanol extract and terpene components from Alismatis Rhizoma (dried rhizome of Alisma orientale). Biol Pharm Bull 1998;21:1317-1321.

18 Imai Y, Matsumura H, Aramaki Y: Hypocholesterolemic effect of alisol A-24-monoacetate and its related compounds in rats. Jpn J Pharmacol 1970;20:222-228.

19 Gomez-Lechon MJ, Donato MT, Martinez-Romero A, Jimenez N, Castell JV, O'Connor JE: A human hepatocellular in vitro model to investigate steatosis. Chem Biol Interact 2007;165:106-116.

20 Liu J, Li YM, Chen SH, Li WP: [an in vitro hepatic steatosis cell model for study of non-alcoholic fatty liver disease]. Zhejiang Da Xue Xue Bao Yi Xue Ban 2009;38:626-629.

21 Jiao HL, Ye P, Zhao BL: Protective effects of green tea polyphenols on human HepG2 cells against oxidative damage of fenofibrate. Free Radic Biol Med 2003;35:1121-1128.

22 Lee S, Kho Y, Min B, Kim J, Na M, Kang S, Maeng H, Bae K: Cytotoxic triterpenoides from Alismatis Rhizoma. Arch Pharm Res 2001;24:524-526.

23 Vidyashankar S, Sandeep VR, Patki PS: Quercetin ameliorate insulin resistance and up-regulates cellular antioxidants during oleic acid induced hepatic steatosis in HepG2 cells. Toxicol In Vitro 2013;27:945-953.

24 Bradbury MW: Lipid metabolism and liver inflammation. I. Hepatic fatty acid uptake: Possible role in steatosis. Am J Physiol Gastrointest Liver Physiol 2006;290:G194-G198.

25 Soardo G, Donnini D, Domenis L, Catena C, De Silvestri D, Cappello D, Dibenedetto A, Carnelutti A, Bonasia V, Pagano C, Sechi LA: Oxidative stress is activated by free fatty acids in cultured human hepatocytes. Metab Syndr Relat Disord 2011;9:397-401.

26 Jarrar MH, Baranova A, Collantes R, Ranard B, Stepanova M, Bennett C, Fang Y, Elariny H, Goodman Z, Chandhoke V, Younossi ZM: Adipokines and cytokines in non-alcoholic fatty liver disease. Aliment Pharmacol Ther 2008;27:412-421.

27 Tessari P, Coracina A, Cosma A, Tiengo A: Hepatic lipid metabolism and non-alcoholic fatty liver disease. Nutr Metab Cardiovasc Dis 2009;19:291-302.

28 Musso G, Gambino R, Cassader M: Recent insights into hepatic lipid metabolism in non-alcoholic fatty liver disease (NAFLD). Prog Lipid Res 2009;48:1-26.

29 Zhou M, Xu A, Tam PK, Lam KS, Chan L, Hoo RL, Liu J, Chow KH, Wang Y: Mitochondrial dysfunction contributes to the increased vulnerabilities of adiponectin knockout mice to liver injury. Hepatology 2008;48:1087-1096.

30 Flechtner-Mors M, George SN, Oeztuerk S, Haenle MM, Koenig W, Imhof A, Boehm BO, Graeter T, Mason RA, Kratzer W, Akinli AS: Association of adiponectin with hepatic steatosis: A study of 1,349 subjects in a random population sample. BMC Res Notes 2014;7:207.

31 Moschen AR, Molnar C, Wolf AM, Weiss H, Graziadei I, Kaser S, Ebenbichler CF, Stadlmann S, Moser PL, Tilg H: Effects of weight loss induced by bariatric surgery on hepatic adipocytokine expression. J Hepatol 2009;51:765-777.

32 Xu A, Wang Y, Keshaw H, Xu LY, Lam KS, Cooper GJ: The fat-derived hormone adiponectin alleviates alcoholic and nonalcoholic fatty liver diseases in mice. J Clin Invest 2003;112:91-100.

33 Bruun JM, Lihn AS, Verdich C, Pedersen SB, Toubro S, Astrup A, Richelsen B: Regulation of adiponectin by adipose tissue-derived cytokines: In vivo and in vitro investigations in humans. Am J Physiol Endocrinol Metab 2003;285:E527-E533.

34 Kadowaki T, Yamauchi T, Kubota N, Hara K, Ueki K, Tobe K: Adiponectin and adiponectin receptors in insulin resistance, diabetes, and the metabolic syndrome. J Clin Invest 2006;116:1784-1792.

35 You M, Considine RV, Leone TC, Kelly DP, Crabb DW: Role of adiponectin in the protective action of dietary saturated fat against alcoholic fatty liver in mice. Hepatology 2005;42:568-577.

36 Zhang BB, Zhou G, Li C: AMPK: An emerging drug target for diabetes and the metabolic syndrome. Cell Metab 2009;9:407-416.

37 Kohjima M, Higuchi N, Kato M, Kotoh K, Yoshimoto T, Fujino T, Yada M, Yada R, Harada N, Enjoji M, Takayanagi R, Nakamuta M: SREBP-1c, regulated by the insulin and AMPK signaling pathways, plays a role in nonalcoholic fatty liver disease. Int J Mol Med 2008;21:507-511.

38 Zhou G, Myers R, Li Y, Chen Y, Shen X, Fenyk-Melody J, Wu M, Ventre J, Doebber T, Fujii N, Musi N, Hirshman MF, Goodyear LJ, Moller DE: Role of AMP-activated protein kinase in mechanism of metformin action. J Clin Invest 2001;108:1167-1174. 


\section{Cellular Physiology Cell Physiol Biochem 2016;40:453-464 \begin{tabular}{ll|l} 
DOI: 10.1159/000452560 & $\begin{array}{l}\text { O 2016 The Author(s). Published by S. Karger AG, Basel } \\
\text { www.karger.com/cpb }\end{array}$
\end{tabular} \\ Zeng et al.: Mechanism of Alisol A 24-Acetate Against Hepatic Steatosis}

39 Xi Y, Wu M, Li H, Dong S, Luo E, Gu M, Shen X, Jiang Y, Liu Y, Liu H: Baicalin attenuates high fat Diet-Induced obesity and liver dysfunction: Dose-Response and potential role of CaMKKbeta/AMPK/ACC pathway. Cell Physiol Biochem 2015;35:2349-2359.

40 Ferre P: The biology of peroxisome proliferator-activated receptors: Relationship with lipid metabolism and insulin sensitivity. Diabetes 2004;53:S43-S50.

41 Tailleux A, Wouters K, Staels B: Roles of PPARs in NAFLD: Potential therapeutic targets. Biochim Biophys Acta 2012;1821:809-818.

42 Minnich A, Tian N, Byan L, Bilder G: A potent PPARalpha agonist stimulates mitochondrial fatty acid betaoxidation in liver and skeletal muscle. Am J Physiol Endocrinol Metab 2001;280:E270-E279.

43 Choi KC, Ryu OH, Lee KW, Kim HY, Seo JA, Kim SG, Kim NH, Choi DS, Baik SH, Choi KM: Effect of PPAR- $\alpha$ and $-\gamma$ agonist on the expression of visfatin, adiponectin, and TNF- $\alpha$ in visceral fat of OLETF rats. Biochem Biophys Res Commun 2005;336:747-753.

44 Alwayn IP, Andersson C, Lee S, Arsenault DA, Bistrian BR, Gura KM, Nose V, Zauscher B, Moses M, Puder M: Inhibition of matrix metalloproteinases increases PPAR-alpha and IL-6 and prevents dietaryinduced hepatic steatosis and injury in a murine model. Am J Physiol Gastrointest Liver Physiol 2006;291:G1011-G1019.

45 Lee WJ, Kim M, Park HS, Kim HS, Jeon MJ, Oh KS, Koh EH, Won JC, Kim MS, Oh GT, Yoon M, Lee KU, Park JY: AMPK activation increases fatty acid oxidation in skeletal muscle by activating PPARalpha and PGC-1. Biochem Biophys Res Commun 2006;340:291-295.

46 Kim MK, Kim SH, Yu HS, Park HG, Kang UG, Ahn YM, Kim YS: The effect of clozapine on the AMPK-ACC-CPT1 pathway in the rat frontal cortex. Int J Neuropsychopharmacol 2012;15:907-917. 